Relations industrielles

Industrial Relations

\title{
Comment étudier un problème, par Roland Caude, Entreprise Moderne d'Édition, Paris, 1968, 117 pp.
}

\section{Geneviève Solasse}

Volume 23, numéro 2, 1968

URI : https://id.erudit.org/iderudit/027912ar

DOI : https://doi.org/10.7202/027912ar

Aller au sommaire du numéro

Éditeur(s)

Département des relations industrielles de l'Université Laval

ISSN

0034-379X (imprimé)

1703-8138 (numérique)

Découvrir la revue

Citer ce compte rendu

Solasse, G. (1968). Compte rendu de [Comment étudier un problème, par Roland Caude, Entreprise Moderne d'Édition, Paris, 1968, 117 pp.] Relations

industrielles / Industrial Relations, 23(2), 373-373.

https://doi.org/10.7202/027912ar

Tous droits réservés (c) Département des relations industrielles de l'Université Laval, 1968
Ce document est protégé par la loi sur le droit d'auteur. L'utilisation des services d'Érudit (y compris la reproduction) est assujettie à sa politique d'utilisation que vous pouvez consulter en ligne.

https://apropos.erudit.org/fr/usagers/politique-dutilisation/ 
a l'autoritarisme des seconds et à la dose d'irrotionnalité qui l'accompagne parfois.

\section{Bernard SOLASSE}

\section{L'entretien d'appréciation, par Norman Maier,} Entreprise Moderne d'Edition, Paris, 1968, 290 poges.

L'entretien d'appréciation est abordé ici comme un excellent moyen de combler périodiquement l'impersonnalité des rapports supérieurs-subordonnés dans la grande entreprise moderne. L'entretien o d'autres fonctions considérées parfois plus importantes, telles apprécier le travail et les attitudes des subordonnés, corriger des positions troubles, régler des conflits particuliers. Puisque l'entretien doit prendre la forme d'un dialogue, il est une occasion particulièrement intéressante pour les deux personnes concernées de se juger mutuellement, de récrienter leur action sans qu'il soit nécessaire de respecter le niveau hiérarchique. Certains diront que l'appréciation sera plus efficace si l'entretien ne comporte aucune appréciation du personnel.

Normon Maier fait plus qu'exposer une nouvelle conception de base des entretiens d'appréciation, il donne des méthodes de dialogue. Ceux qui recherche les solutions toutes prêtes en trouveront. Six formes de dialogues sont présentées et onalysées systématiquement. Chaque mot, pourrait-on dire, est pesé, chaque attitude est étudiée non seulement en fonction des objectifs poursuivis par le supérieur, mais aussi en fonction des réactions et des besoins du subordonné. D'aucun comprendront qu'on ne peut composer à l'avance un dialogue qui se veut spontané et qui met surtout en présence des personnes qui se connaissent souvent très mal. D'ailleurs, chaque subordonné est un type particulier, non seulement par les situations différentes qu'il a connues, mais aussi par sa personnalité même, so façon de comprendre les choses et de réagir face à son supérieur. Attention donc à ces formules magiques!

Chacun des six dialogues commentés par Norman Maier peut servir beaucoup plus adéquatement d'instrument pour critiquer, commenter et analyser les dialogues que nous avons l'occasion de mener nous-mêmes. En effet, l'auteur dégage après chaque dialogue les grandes variables et l'exploitation qui en est faite. Ces variables pourront servir à tout le monde car elles sont les principes de base de tout entretien d'appré- ciation, par exemple lo participation, I'information, l'évaluation...

Le livre de Norman Maier portera davantage de fruits $s^{\prime} i l$ réussit simplement ò susciter de nouvelles mentalités et attitudes de la part des supérieurs à l'endroit des subordonnés, surtout à l'occasion de l'entretien périodique d'appréciation qui peut être soit une excellente occasion de nouer des ropports amicaux, soit une critique bête qui créera plus de tension qu'elle n'en déliera. Le succès de la méthode est dans l'esprit plus que dans les formules neuves.

\section{L.-René PARENTEAU}

Comment étudier un problème, par Roland Caude, Entreprise Moderne d'Edition, Poris, 1968, 117 pp.

Ce petit livre bien écrit évite le piège du racolage vulgaire en dépit de ce que pouvait laisser craindre son titre. Mais, à notre avis, le lecteur peu cultivé ou peu expérimenté auxquels les conseils donnés pourraient sans doute servir, se laissera rebuter par les termes abstraits, tels qu' a anolyse » et "synthèse ", sons compter les références à Descartes; en revanche, les a cadres d'entreprise " auxquels s'adresse particulièrement cet ouvrage, nous dit-on, auront l'impression de retrouver des vérités que leurs études ou leur expérience quotidienne ont rendues pour eux depuis longtemps évidentes.

\section{Geneviève SOLASSE}

\section{Initiation aux nouvelles techniques de ges- tion industrielle, par André Olmi, Entre- prise Moderne d'Edition, Poris, 1967, 60 pp.}

L'auteur se propose de faire un tour d'horizon des principaux problèmes industriels qui peuvent être abordés et résolus par les techniques économiques. II insiste sur la nécessité d'aborder ces problèmes ovec un esprit scientifique qui consiste à \& soutenir le raisonnement humain, plus ou moins intuitif et empirique, par un raisonement mathématique $»$. On a donc de plus en plus recours, dans la gestion économique des entreprises, à la recherche opérationnelle définie par plusieurs comme la théorie de la décision appliquée ou comme une méthode scientifique dont le but est de fournir au personnel exécutif des éléments quantitatifs pouvant servir de base aux décisions concernant les opérations qu'il dirige. 